\title{
The Research into the Training of the Meta-cognitive Strategy of College Students
}

\author{
Zhen Zhou \\ Foreign Language Department \\ Jiangxi Institute of Education \\ Nanchang, Jiangxi, China, 330032 \\ E-mail: zoye100@126.com
}

\begin{abstract}
-the study on language learning strategies has become the focus of the second language acquisition research, and receives extensive attention from the linguists and educators. Besides, the meta-cognitive strategy is an important part of language learning strategies and it is also closely related to the English learning process. The article attempts to understand the condition of the meta-cognitive strategy use of college students, and explores whether the meta-cognitive strategy training can improve students' meta-cognitive strategy level and English learning achievements through investigating the students in the Chinese department and chemistry department of Jiangxi Institute of Education with the metacognitive strategy questionnaire investigation and a fifteenweek meta-cognitive strategy training. The study aims to improve the quality of the English teaching in colleges.
\end{abstract}

Keywords- meta-cognitive strategy; training; English achievement

\section{INTRODUCTION}

The meta-cognition refers to self-awareness, self-control, self-evaluation and regulation of the cognitive processes using the learner's own cognitive system as the object of cognition [1]. The meta-cognitive strategy is an important part of the language learning strategy, and has been highly concerned by experts and scholars in the field of the second language study [2-4]. The research on the meta-cognition and learning activities shows that the meta-cognition is a good learning skill suitable for various learning tasks [5-7]. Some domestic research indicates that the frequency of students' meta-cognitive strategy use is not high [8-10]. The study also confirms that the meta-cognition and students' academic achievement is correlated [11-16]. However, Qin Xiaojing's study finds that the meta-cognitive strategy use is not associated with their English learning strategies [17].

In the recent years the meta-cognitive strategy training has also been the focus of scholars and experts at home and abroad. Carrell's experimental results about the training of the meta-cognitive reading strategies of 26 students whose English is their second language suggest that the metacognitive strategy training is effective to improve the reading level[18]. Bruce and Robinson conduct two consecutive experiments on 70 poor readers in the primary school, and the results show that some significant training effect exist under the experimental conditions, but the effect of the classroom strategy teaching and training is not obvious[19]. And the results of the training many scholars in China have made on the meta-cognitive strategy indicate that the metacognitive strategy training has a certain effect. Pan Liping's study finds that the reading meta-cognitive strategy training can improve the subjects' consciousness of the metacognitive strategy [20]; Li Jun's studies show that the metacognitive strategy instruction can help those backward students improve their English learning, and then effectively improve their English achievement[15]; Yang Jianding thinks that the meta-cognitive strategy training is helpful to improve the listening comprehension ability[21]. However, Liu Ying's study demonstrates that the short-term strategy training can strengthen the meta-cognition and reading strategy use effectively, but the improvement of the reading performance has not achieved a very significant effect [22].

However, so far, as for the study of meta-cognitive strategies, the research object is generally focused on the English major undergraduates in some key universities, and the studies usually combine the research of the metacognitive strategy and the listening comprehension or the reading teaching or writing teaching. And the empirical research to study the relationship between the general use of meta-cognitive strategies and English learning achievement is particularly scarce, which takes the college students as the research object, and carries on the training of meta-cognitive strategies. At present the quality of the current college English teaching is not high, thus the purpose of this research is to find some effective ways to improve the college English teaching quality.

\section{RESEARCH METHODS}

\section{A. Investigation Object}

A questionnaire survey is conducted on the three grades of students in the Chinese department and chemistry department in Jiangxi Institute of Education in China. 480 copies of questionnaires are distributed in class and 460 copies of effective questionnaires back on the spot, and the questionnaire response rate is $96 \%$.

\section{B. The Experimental Object}

The experimental class is Class 1 , and the control class is Class 2. (The students are 2011 chemistry majors).

\section{The survey instrument}

In order to make a comprehensive understanding of the college students' meta-cognitive strategy use, this study adopts both qualitative and quantitative research methods 
through the questionnaire survey, analysis of test papers, interviews, data collection, and the statistical analysis is performed by SPSS18.0 software.

- Quantitative research. Using the meta-cognitive awareness scale "The Meta-cognitive Awareness Inventory (MAI)" which Schraw and Dennison designs[6]. The performance in PET Band Three is used in this study to distinguish between the high achievers and low achievers. The questionnaire data using the Likert 5 point score scale.

- Qualitative research: Interview. 5 students in each grade of the subjects are randomly selected (a total of 30 students), and they will be chosen as the interviewees. Each interview time lasts for 5 minutes, aiming to make a reasonable explanation for filling in the questionnaire.

- Training method. The content of the training mainly concentrates on the three meta-cognitive knowledge and five meta-cognitive strategies. The metacognitive strategy training lasts from the third week to the seventeenth week, altogether fifteen weeks. In addition to the experimental training in the English class every week, a class is added specifically for the meta-cognitive strategy training for the experimental class students. The training takes the form as follows: establishing the cognitive strategy archives, expert lectures, students' speeches, theme class meeting, case analysis, discussion, and debate, in which the focus is that the teacher sets specific tasks for students to complete.

\section{THE FINDINGS AND ANALYSIS}

\section{A. The Meta-cognitive Strategies and English Achievement}

The descriptive statistics of the meta-cognitive strategies and the English achievement in the survey (Table I) indicates that all the means of the perspective meta-cognitive strategies are low, and college students lack meta-cognitive knowledge, and the meta-cognitive strategy use level is generally low. Besides, their English foundation is weak, and the dispersion of the scores is large, the highest score is 91 points, the lowest only is 39 points, and the achievement gap is great $(\mathrm{SD}=11.7966)$. Specifically, in the meta-cognitive knowledge, according to the average ranking, the order is: declarative knowledge, procedural knowledge, and conditional knowledge. This suggests that the students understand some meta-cognitive knowledge, but they have little understanding of automation procedural skills. And the conditional knowledge is more deficient, which reflects that the students lack the consciousness in the meta-cognitive strategy knowledge, and they only have some understanding of the declarative knowledge. In the use of meta-cognitive strategies, according to frequency of use, the order is as follows: correcting strategy, information strategy, planning strategy, evaluation strategy and monitoring strategy. The monitoring strategy is of the lowest level, showing that students cannot control and manage their English learning well. What's more, the level of the evaluation strategy is low, therefore it can be concluded that students can not make a proper evaluation timely; Students' English learning has a lot of freedom. The level of students' planning strategy is very low, and the mean is below 3, which indicates that the students' English learning has great blindness. The level of the correcting strategy and information strategy is relatively high, demonstrating that the students can discover some remedies for the problems in English learning timely; They can collect and process the learning information better.

TABLE I. DESCRIPTIVE STATISTICS OF META-COGNITIVE KNOWLEDGE, META-COGNITIVE STRATEGIES AND ENGLISH ACHIEVEMENT $(\mathrm{N}=460)$

\begin{tabular}{ccccc}
\hline Item & Min & Max & Mean & $\begin{array}{c}\text { Std. } \\
\text { Deviation }\end{array}$ \\
\hline $\begin{array}{c}\text { General meta- } \\
\text { cognitive knowledge } \\
\text { Meta-cognitive }\end{array}$ & 1.56 & 3.87 & 3.0108 & .50962 \\
$\begin{array}{c}\text { strategy } \\
\text { English achievement }\end{array}$ & 1.81 & 4.11 & 3.0506 & .46592 \\
Declarative knowledge & 1.67 & 4.22 & 3.1832 & .5380 \\
Procedural knowledge & 1.40 & 4.00 & 2.7754 & .6370 \\
Conditional knowledge & 1.60 & 4.20 & 3.0737 & .5948 \\
Correcting strategy & 2.40 & 4.60 & 3.4070 & .6369 \\
Information strategy & 2.00 & 4.22 & 3.1384 & .4822 \\
Planning strategy & 1.67 & 4.17 & 2.9854 & .5663 \\
Assessment strategy & 1.17 & 4.17 & 2.8626 & .4608 \\
Monitoring strategy & 1.14 & 4.14 & 2.8596 & .5868 \\
\hline
\end{tabular}

\section{B. The Situation Before and After the Training of Meta-} cognitive Strategies

Before the training, through the independent sample t-test for the control class and the experimental class, the results (Table II) show that there is no significant difference between the two classes in all the aspects of the metacognitive knowledge and meta-cognitive strategies and therefore the experimental and control class can be compared together. After the training, the paired sample t-test results comparing the control group before and after the training show in all aspects of the cognitive strategy, there is no significant difference existing in the control class. Because the control class has not received training, this result is expected, and very reasonable. After the fifteen week metacognitive strategy training is completed, the independent sample t-test result of the experimental class and control class presents that in the general meta-cognitive knowledge, general meta-cognitive strategies, procedural knowledge, conditional knowledge, correcting strategy and information strategy there are remarkable differences, but there is no significant difference in the English achievement. Thus, the training has a certain effect, which can boost students' metacognitive knowledge and strategy level. After the training, through the paired samples t-test comparing all the items of the meta-cognitive strategy of the experimental class, the result demonstrates that there is distinct difference in the general meta-cognitive knowledge, general meta-cognitive strategies, procedural knowledge, conditional knowledge, correcting strategy and information strategy, but there is no significant difference in the English achievement. And this result is consistent with that in the independent sample t-test of the experimental class and the control class. The results show that the meta-cognitive training can improve students' 
meta-cognitive knowledge and meta-cognitive strategy use level, such as general meta-cognitive knowledge, general meta-cognitive strategies, procedural knowledge, conditional knowledge, correcting strategy, planning strategy, evaluation strategy, monitoring strategy and information strategy to a certain degree, but fails to significantly improve the metacognitive declarative knowledge level, and also fails to significantly enhance their English achievement, which is consistent with Liu Ying's finding [22]. The reason why the English scores do not significantly improve may lie in the fact that the teacher's training quality is limited, the training time is fairly limited, students' English basis is poor, and students' English achievements meet some bottleneck.

TABLE II. TRAINING BEFORE AND AFTER THE EXPERIMENTAL CLASS AND THE CONTROL CLASS INDEPENDENT SAMPLE T-TEST AND PAIRED SAMPLES TTEST

\begin{tabular}{|c|c|c|c|c|c|c|c|c|c|c|c|}
\hline & & \multicolumn{2}{|c|}{ Mean } & \multicolumn{2}{|c|}{ SD } & \multicolumn{2}{|c|}{$\begin{array}{l}\text { Independent t-test } \\
\text { (Pre-E\& Post-C) }\end{array}$} & \multicolumn{2}{|c|}{$\begin{array}{c}\text { Independent t-test } \\
\text { (Post-E\&Post-C) }\end{array}$} & \multicolumn{2}{|c|}{$\begin{array}{c}\text { Paired t-test } \\
(\text { PreE \& post E) }\end{array}$} \\
\hline & & Pre & Post & Pre & Post & $t$ & sig & $t$ & sig & $t$ & sig \\
\hline \multirow[t]{2}{*}{ General meta-cognitive knowledge } & $\mathrm{C}$ & 3.0341 & 3.1563 & 6349 & .6451 & \multirow{2}{*}{1.078} & \multirow{2}{*}{.051} & \multirow{2}{*}{-1.175} & \multirow{2}{*}{.045} & -1.468 & .164 \\
\hline & $\mathrm{E}$ & 3.0172 & 3.3094 & .7085 & .7390 & & & & & -3.521 & .044 \\
\hline \multirow[t]{2}{*}{ Meta-cognitive strategy } & $\mathrm{C}$ & 3.6300 & 3.7400 & .5236 & .5327 & \multirow{2}{*}{1.156} & \multirow{2}{*}{.069} & \multirow{2}{*}{-1.467} & \multirow{2}{*}{.039} & -.932 & .813 \\
\hline & $\mathrm{E}$ & 3.0300 & 3.2750 & 6418 & .6132 & & & & & -.873 & .026 \\
\hline \multirow[t]{2}{*}{ English achievement } & $\mathrm{C}$ & 68.9498 & 68.9573 & .3837 & .3936 & \multirow{2}{*}{2.631} & \multirow{2}{*}{.323} & \multirow{2}{*}{-2.200} & \multirow{2}{*}{.061} & -2.847 & .317 \\
\hline & $\mathrm{E}$ & 65.974 & 70.1527 & .4553 & .4549 & & & & & -2.913 & .054 \\
\hline \multirow[t]{2}{*}{ Declarative knowledge } & $\mathrm{C}$ & 3.1526 & 3.2314 & .6723 & .9235 & \multirow{2}{*}{1.914} & \multirow{2}{*}{.041} & \multirow{2}{*}{-1.544} & \multirow{2}{*}{.063} & -2.483 & .417 \\
\hline & $\mathrm{E}$ & 3.0537 & 3.4872 & .7867 & 6871 & & & & & -3.679 & .068 \\
\hline \multirow[t]{2}{*}{ Procedural knowledge } & $\mathrm{C}$ & 2.7300 & 2.7416 & 6300 & .5730 & \multirow{2}{*}{-1.132} & \multirow{2}{*}{.053} & \multirow{2}{*}{-.853} & \multirow{2}{*}{.037} & -2.315 & .309 \\
\hline & $\mathrm{E}$ & 2.8468 & 3.1928 & 6900 & .6532 & & & & & -3.731 & .021 \\
\hline \multirow[t]{2}{*}{ Conditional knowledge } & $\mathrm{C}$ & 3.1743 & 3.1856 & .6450 & .6441 & 3432 & 147 & -2657 & 003 & -3.432 & .147 \\
\hline & & 3.0987 & 3.3247 & .7704 & .7839 & 5.452 & $.14 /$ & -2.051 & .000 & -2.467 & .016 \\
\hline Correcting strategy & $\mathrm{C}$ & 3.3992 & 3.4909 & .4623 & .4531 & -1.065 & .783 & $-3,436$ & 017 & -1.065 & .783 \\
\hline & & 3.4793 & 3.6846 & .6768 & .7877 & -1.005 & .105 & & & -1.637 & .035 \\
\hline Information strategy & $\mathrm{C}$ & 3.1397 & 3.8700 & .8053 & .7893 & -2643 & 853 & -1359 & 031 & 2.643 & .853 \\
\hline & & 3.1405 & 3.1678 & .6581 & .5467 & & & & & -2.932 & .004 \\
\hline Planning strategy & $\mathrm{C}$ & 2.9870 & 2.9906 & .4773 & .4713 & 1.354 & .631 & -325 & 039 & 1.354 & .631 \\
\hline & & 2.9871 & 3.1560 & .6176 & .5036 & -1.632 & .017 & -.325 & .039 & -2.743 & .46 \\
\hline Assessment strategy & $\mathrm{C}$ & 2.8936 & 2.8742 & .5013 & .5229 & -1.587 & .071 & -2375 & 023 & -1.587 & .071 \\
\hline & $\mathrm{E}$ & 2.8542 & 3.0164 & .6731 & .5444 & -1.371 & .003 & -2.515 & .025 & -1.421 & .043 \\
\hline Monitoring strategy & $\begin{array}{l}\mathrm{C} \\
\mathrm{F}\end{array}$ & 2.8541 & 2.8467 & .5137 & .7402 & .484 & .821 & -.494 & .019 & .484 & .821 \\
\hline & & 2.8502 & 2.9078 & .6343 & .6742 & -.537 & .014 & -.494 & .019 & -2.490 & .041 \\
\hline
\end{tabular}

(C: control class E: experimental class Total score $=100.00)$

\section{CONCLUSION}

Through the above analysis, conclusions can be drawn through the survey. First, the using level of the college students' meta-cognitive knowledge and meta-cognitive strategy is generally low, and the meta-cognitive strategies score lower than the meta-cognitive knowledge. And their English foundation is weak with big achievement gaps. In the meta-cognitive knowledge, the declarative knowledge ranks first. In the use of meta-cognitive strategies, monitoring strategies using is of the lowest level, indicating that students' self-control is not enough, and their learning is blind; Second, the meta-cognition training can improve students' meta-cognitive strategy level, such as the general meta-cognitive knowledge, the general meta-cognitive strategies, procedural knowledge, conditional knowledge, correcting strategy and information strategy to a certain degree, but fails to improve the students' English proficiency.

These results may have some implications for college and university English teaching and other levels of English teaching. First of all, education departments, teachers and students should face the situation that the students' metacognitive strategy use level is low, should pay more attention to the important impacts students' meta-cognitive strategies on the English learning activities and strive to improve students' level of the meta-cognitive strategy; Secondly, the English teachers in the English teaching should also assume the task of meta-cognitive strategy training, if necessary, conduct targeted meta-cognitive strategy training on the students; Finally, the students should change the understanding of the English learning, improve their interest in learning English, actively cooperate with the English teachers in the English learning and the meta-cognitive strategy training, make great efforts to improve the level of meta-cognitive knowledge and meta-cognitive strategy of their own, so as to achieve the ultimate goal of improving English achievement.

\section{ACKNOWLEDGMENT}

This study was financially supported by the Jiangxi Education Science "12th Five-Year" planning issues (11YB104). 


\section{REFERENCES}

[1] J. H. Flavell, "First Discussant's Comments: What is Memory Development?" Human Development, vol. 14, May. 1971, pp. 272278.

[2] N. J. Anderson, "The Role of Meta-cognition in Second Language Teaching and Learning,” ERIC Digest, Apr. 2002, pp. 110-112.

[3] Zujia He, "An Experimental Study on Meta-cognitive Strategy Training in Listening Class ,”. Foreign language audio-visual Teaching, vol. 41, Apr. 2005, pp. 56-61.

[4] Wenyu Liu, "The Analysis Research into the Influence of the Metacognitive training on Chinese Students' Writing," Foreign language education, vol. 32, Apr. 2011, pp. 60-63.

[5] J. Nisbet, J. Shucksmith, "Learning Strategies". Boston: Routledge \& K. Pau,1 1986.

[6] G. Schraw and R. S. Dennison, "Assessing Meta-cognitive Awareness,"Contemporary Educational Psychology, vol. 19, June. 1994, pp. 460-470.

[7] W. Rivers, "Autonomy at All Costs: An Ethnography of Metacognitive Self-assessment and Self-management among Experienced Language Learners,” Modern Language Journal, vol. 10, Feb. 2001, pp. 279-290.

[8] Huijun Liu, "The Relationship between the Meta-cognition and English Reading," Foreign Language and Foreign Language Teaching, vol. 18, Dec. 2004, pp.24-26.

[9] Xuan Zhang, "The Investigation of the Meta-cognitive Strategy of English Majors in the Fundamental Learning Stage," Journal of PLA Foreign Languages Institute, vol.16, Mar. 2005, pp. 59-62.

[10] Yang Hu and Weimin Zhang, "The Using Ability of College English Learners," [J]. Foreign Language Education, vol. 23, May. 2006, pp. 59-62.

[11] Qiufang Wen, "The Difference between English Successful Students and Unsuccessful Students," Foreign Language Teaching and Research, vol. 23, Mar.1995, pp. 61-66.
[12] Qiufang Wen, "The Changing Trend and Characteristics of University Students' Learning Strategy," Foreign Language and Foreign Language Teaching, vol. 23,Apr. 1996, pp. 43-46.

[13] Qiufang Wen \& R. K Johnson, "L2 Learner Variables and English Achievement: A Study of Tertiary-level English Majors in China," Applied Linguistics, vol. 18, Jan. 1997, pp. 55-60.

[14] Wenjun Lu, "The Relationship between the Meta-cognitive Strategies and the English writing," Foreign Language Teaching and Research, vol. 11, Sept. 2006, pp. 25-27.

[15] Jun Li and Hangying Ni, "The Intervention Research of the Metacognitive Strategy of Non-English Majors," Foreign Language World, vol. 43, Jan. 2007, pp. 49-53.

[16] J. M. O'Malley and A. U. Chamot, Learning Strategies in Second Language Acquisition. Cambridge University Press, 1990.

[17] Xiaoqing Qin, "The Characteristics of Postgraduates using English Learning Strategy," Foreign Language Education, vol. 23, Jan.1998, pp. 53-56.

[18] P. L. Carrell, "Meta-cognitive strategy training for ESL reading," TESOL Quarterly, vol. 23, Dec.198, pp. 647-678.

[19] M. E. Bruce and G. L. Robinson, "Effectiveness of a Meta-cognitive Reading Program for Poor Readers," Educational Research, vol. 10, Jan. 2000, pp.1-20.

[20] Liping Pan, "The Experimental Research into the Teachability of the Meta-cognitive Strategy in the Second Language Reading Class," Foreign Language Education, vol. 23, Jan.. 2006, pp. 49-54.

[21] Jianding Yang, "The Meta-cognitive Strategy Training in the Listening Teaching," Foreign Language Education, vol. 21, Apr. 2003, pp. 65-69.

[22] Ying Liu, "The Research into the Effect of the Meta-cognitive Strategy Training on the Under-achievers in the College English Reading," Foreign Language and Foreign Language Teaching, vol.14, Oct. 2009, pp. 38-41. 